\title{
Cardioprotective Effect of the Aqueous Extract of Lavender Flower against Myocardial Ischemia/Reperfusion Injury
}

\author{
Dong Wang, ${ }^{1}$ Xin Guo, ${ }^{2}$ Mingjie Zhou, ${ }^{1}$ Jichun Han, ${ }^{3}$ Bo Han, ${ }^{3}$ and Xiling Sun ${ }^{4}$ \\ ${ }^{1}$ Shandong Provincial Qianfoshan Hospital, Jinan, Shandong 250014, China \\ ${ }^{2}$ Affiliated Traditional Medical Hospital of Xinjiang Medical University, Urumqi 830000, China \\ ${ }^{3}$ School of Pharmacy, Shihezi University, Shihezi 832002, China \\ ${ }^{4}$ School of Integrated Traditional Chinese and Western Medicine, Binzhou Medical University, Yantai 264000, China
}

Correspondence should be addressed to Xiling Sun; sunxiling@sohu.com

Received 6 April 2014; Revised 31 May 2014; Accepted 1 June 2014; Published 29 June 2014

Academic Editor: Wang Chunming

Copyright (C) 2014 Dong Wang et al. This is an open access article distributed under the Creative Commons Attribution License, which permits unrestricted use, distribution, and reproduction in any medium, provided the original work is properly cited.

\begin{abstract}
This study was conducted to evaluate the cardioprotective property of the aqueous extract of lavender flower (LFAE). The myocardial ischemia/reperfusion (I/R) injury of rat was prepared by Langendorff retrograde perfusion technology. The heart was preperfused with $\mathrm{K}-\mathrm{H}$ solution containing LFAE for $10 \mathrm{~min}$ before 20 minutes global ischemia, and then the reperfusion with $\mathrm{K}-\mathrm{H}$ solution was conducted for $45 \mathrm{~min}$. The left ventricular developed pressure (LVDP) and the maximum up/downrate of left ventricular pressure $\left( \pm d p / d t_{\max }\right)$ were recorded by physiological recorder as the myocardial function and the myocardial infarct size was detected by TTC staining. Lactate dehydrogenase (LDH) and creatine kinase (CK) activities in the effluent were measured to determine the myocardial injury degree. The superoxide anion dismutase (SOD) and malondialdehyde (MDA) in myocardial tissue were detected to determine the oxidative stress degree. The results showed that the pretreatment with LFAE significantly decreased the myocardial infarct size and also decreased the LDH, CK activities, and MDA level, while it increased the LVDP, $\pm d p / d t_{\max }$, SOD activities, and the coronary artery flow. Our findings indicated that LFAE could provide protection for heart against the I/R injury which may be related to the improvement of myocardial oxidative stress states.
\end{abstract}

\section{Introduction}

Cardiovascular disease is common and results in much of mortality of people throughout the world. Acute myocardial infarction is particularly formidable in cardiovascular disease cases, coronary artery stenosis is the initial factor that sets off a chain reaction, and the consequence is myocardial necrosis caused by conditions of acute continuous ischemia and hypoxia. Timely and effective recovery of demand of blood supply is an effective method that is able to minimize the heart injuries. Paradoxically, reperfusion itself can cause myocardial injury and cardiac dysfunction, referred to as "reperfusion injury" [1-3]. As a consequence, relieving the ischemic reperfusion injury can be seen as an additional method to secure the heart against cardiovascular disease [4].

Ischemia-reperfusion injury refers to reducing organ of blood donation for a period of time, there will be damage during reperfusion. Doctors gradually found that the main factors that cause damage to an organ, not ischemia itself, but reperfusion. In the process of reperfusion, tissue cells produce oxygen free radicals in excess. Oxidative stress is an important way involved in I/R injury $[5,6]$. Several studies have shown that increased expression of antioxidant enzymes will protect against postischemic injury. It has been reported that antioxidants vitamin E, catalase (CAT), melatonin, and superoxide dismutase (SOD) defend the heart against I/R injury. From another aspect, it confirms that the oxidative stress has been involved in ischemia/reperfusion process $[7,8]$.

Lavender as a traditional botanical medicine has been applied for many years [9]; people in many countries and regions from ancient times employed lavender as an effective medicine to treat diseases; it has many beneficial effects consisting of anti-inflammatory [10], antioxidant [11], 
antibacterial [12], antisenile dementia [13], and anxiolytic, which is particularly evident [14]. The purpose of our study was to detect the protective effect of aqueous extract of lavender flowers on the heart.

\section{Material and Methods}

2.1. Plant Material. The flowers of Lavandula angustifolia Mill were collected in Yili, Xinjiang, China, and the material authenticity was established by one of the authors and later confirmed by a botanist.

2.2. Preparation of Extract. Dried flowers of Lavandula angustifolia Mill were washed in distilled water and air-dried in the shade; flowers were extracted with warm distilled water (DW) (DW: material, $10: 1, \mathrm{v} / \mathrm{w}$ ) twice in an incubator at $80^{\circ} \mathrm{C}$ for $1.5 \mathrm{~h}$. The hot-water extract was filtered through a $2 \mu \mathrm{m}$ pore sterile filter paper. The combined filtrates were concentrated in a vacuum at $60^{\circ} \mathrm{C}$, and the resulting filtrates were amounted to $5 \times 10^{2} \mathrm{mg} / \mathrm{mL}$ crude drug.

2.3. Animals and Experimental Groups. Male Wistar rats (250-280 g) were obtained from Xinjiang Medicine University Medical Laboratory Animal Center (SDXK (new) 2011004). All experimental procedures were approved by the Institutional Animal Care and Use Committee of National Institute Pharmaceutical Education and Research.

The rats were randomly divided into three groups: control group (Sham), I/R group, and aqueous extract of lavender flower (LFAE) treatment group. Hearts in control group were uninterruptedly perfused with $\mathrm{K}-\mathrm{H}$ buffer purely for the $95 \mathrm{~min}$. I/R group hearts were perfused firstly for $30 \mathrm{~min}$ and then we Suspended the infusion for $20 \mathrm{~min}$ and reperfusion for $45 \mathrm{~min}$. Hearts in treatment groups were perfused firstly for $20 \mathrm{~min}$ instead of $\mathrm{K}-\mathrm{H}$ buffer with LFEA $(1 \mathrm{mg} / \mathrm{mL})$ for $10 \mathrm{~min}$ and then we Suspended the infusion for $20 \mathrm{~min}$ and reperfusion for $45 \mathrm{~min}$.

2.4. Isolated Rat Heart Preparation. The male Wistar rats (250-280 g) were anesthetized by an intraperitoneal injection of $60 \mathrm{mmol} / \mathrm{L}$ chloral hydrate $(0.35 \mathrm{~g} / \mathrm{kg})$. To anticoagulate, $250 \mathrm{U} / \mathrm{kg}$ of heparin was given as a sublingual venous injection to the rats. After a few minutes, we performed the thoracic surgery on rat to remove heart. we cut the ribs and opened the chest, Then cut off the blood vessels and obtained the heart and then put the heart into pre-cooling $\mathrm{K}-\mathrm{H}$ solution, squeezed out the blood gently. After that, the heart was excised quickly and immediately mounted on Langendorff's apparatus. The hearts were immersed in icecold K-H buffer $\left(120 \mathrm{mM} \mathrm{NaCl}, 1.2 \mathrm{mM} \mathrm{KH} \mathrm{KO}_{4}, 1.2 \mathrm{mM}\right.$ $\mathrm{CaCl}_{2}, 1.2 \mathrm{mM} \mathrm{MgSO}_{4}, 25 \mathrm{mM}$ sodium acetate, and $11 \mathrm{mM}$ glucose, $\mathrm{pH7.4)}$ equilibrated with a gas mixture comprised of $95 \% \mathrm{O}_{2} / 5 \% \mathrm{CO}_{2}$. Immediately, the heart was connected to the Langendorff apparatus which was maintained at $37^{\circ} \mathrm{C}$ [15], and then we cut the left atrial appendage and inserted the latex balloon filled with water into the left ventricle through the left atrial appendage. Hemodynamic parameters will be displayed on the recorder screen, finally.
TABLE 1: Effect of the aqueous extract of lavender flower (LFAE) on levels of CK and LDH in coronary flow of ischemia/reperfusion injury $(\bar{x} \pm s, n=8)$.

\begin{tabular}{lccc}
\hline \multirow{2}{*}{ Groups } & \multirow{2}{*}{ Before ischemia } & \multicolumn{2}{c}{ Reperfusion } \\
& & $20 \mathrm{~min}$ & $45 \mathrm{~min}$ \\
\hline CK (U/L) & & $17.01 \pm 1.37$ & $18.57 \pm 1.31$ \\
Control & $15.59 \pm 1.35$ & $45.25 \pm 3.59^{* *}$ & $50.36 \pm 2.63^{* *}$ \\
I/R & $14.98 \pm 1.09$ & $21.26 \pm 2.00^{\# \#}$ & $30.63 \pm 2.28^{\# \#}$ \\
LFAE & $15.67 \pm 1.05$ & & \\
LDH (U/L) & & $13.23 \pm 1.80$ & $14.48 \pm 1.07$ \\
Control & $12.34 \pm 1.13$ & $30.91 \pm 2.62^{* *}$ & $37.68 \pm 2.01^{* *}$ \\
I/R & $12.63 \pm 1.17$ & $21.39 \pm 1.33^{\# \#}$ & $27.60 \pm 1.55^{\# \#}$ \\
LFAE & $13.06 \pm 0.83$ & &
\end{tabular}

${ }^{* *} P<0.01$, compared with control group; ${ }^{\# \#} P<0.01$, compared with I/R group.

TABLE 2: Effects of LFAE on SOD activity and MDA level. Values are means with their standard deviation $(\bar{x} \pm s, n=8)$.

\begin{tabular}{lccc}
\hline \multirow{2}{*}{ Group } & \multirow{2}{*}{ Dosage $\left(\mathrm{mg} \cdot \mathrm{mL}^{-1}\right)$} & \multicolumn{2}{c}{ After reperfusion } \\
& & SOD $(\mathrm{U} / \mathrm{mgPr})$ & $\mathrm{MDA}(\mu \mathrm{mol} / \mathrm{mgPr})$ \\
\hline Control & - & $9.29 \pm 0.66$ & $190.78 \pm 11.93$ \\
$\mathrm{I} / \mathrm{R}$ & - & $3.60 \pm 0.28^{* *}$ & $433.66 \pm 29.16^{* *}$ \\
LFAE & 1 & $7.46 \pm 0.51^{\# \#}$ & $231.41 \pm 18.93^{\# \#}$ \\
${ }^{* *} P<0.01$, compared with control group; ${ }^{\# \#} P<0.01$, compared with $\mathrm{I} / \mathrm{R}$ \\
group.
\end{tabular}

2.5. Measurement of Heart Hemodynamic Parameters. The hemodynamic parameters were accurately detected by a signal collecting system (PC Power lab with Chart 5 software, $4 \mathrm{~S} \mathrm{AD}$ instruments). The following functional parameters were measured: left ventricular systolic pressure (LVSP), left ventricular end-diastolic pressure (LVEDP, LVDP $=$ LVSP LVEDP), $\pm d p / d t_{\max }$ (reflecting the important indicators of left ventricular systolic function and diastolic function), and heart rate (HR) were detected uninterruptedly using $4 \mathrm{~S} \mathrm{AD}$ instruments biology polygraph (Power lab, Australia). The coronary flow (CF) was detected using a flow meter with an in-line probe (model T106, Transonic).

2.6. Enzymes Activities Assays. To determine creatine kinase (CK) and lactate dehydrogenase (LDH) activity in the perfusate, samples were collected from the coronary effluent before $20 \mathrm{~min}$ ischemia and after $20 \mathrm{~min}$ and $45 \mathrm{~min}$ of reperfusion. $\mathrm{LDH}$ and $\mathrm{CK}$ were assayed spectrophotometrically using LDH and CK kits (Nanjing Jiancheng Bioengineering Institute, Nanjing, China).

2.7. Evaluation of Myocardial Infarct Size. In the wake of frozen, the hearts were cut into five slices along the transverse direction, and every piece was $2 \mathrm{~mm}$ thick. We put the sliced hearts in TTC with the concentration of $1 \%$ to be incubated for 15 minutes and we turned over the hearts once in this process. When the TTC staining was over, the heart slices were dried with filter paper, and then these slices were covered in formalin solution for 15 minutes, Finally, these 
TABle 3: Supplemental data for Figure 1.

\begin{tabular}{|c|c|c|c|}
\hline \multirow{2}{*}{ Group } & \multicolumn{3}{|c|}{ Reperfusion } \\
\hline & $15 \mathrm{~min}$ & $30 \mathrm{~min}$ & $45 \mathrm{~min}$ \\
\hline \multicolumn{4}{|l|}{$\overline{L V D P}$} \\
\hline Control & $92.88 \pm 4.76$ & $88.13 \pm 4.01$ & $85.63 \pm 4.81$ \\
\hline $\mathrm{I} / \mathrm{R}$ & $46.38 \pm 3.20^{* *}$ & $52.67 \pm 2.83^{* *}$ & $44.22 \pm 3.60^{* *}$ \\
\hline LFAE & $72.37 \pm 3.16^{\# \#}$ & $69.38 \pm 2.83^{\# \#}$ & $58.88 \pm 3.06^{\# \#}$ \\
\hline \multicolumn{4}{|l|}{$+d p / d t_{\max }$} \\
\hline Control & $94.63 \pm 4.69$ & $89.63 \pm 3.96$ & $83.62 \pm 3.93$ \\
\hline $\mathrm{I} / \mathrm{R}$ & $48.25 \pm 2.71^{* *}$ & $46.13 \pm 2.70^{* *}$ & $43.50 \pm 2.62^{* *}$ \\
\hline LFAE & $66.75 \pm 3.54^{\# \#}$ & $63.38 \pm 2.87^{\# \#}$ & $60.63 \pm 3.02^{\# \#}$ \\
\hline \multicolumn{4}{|l|}{$-d p / d t_{\min }$} \\
\hline Control & $91.25 \pm 4.10$ & $89.50 \pm 3.77$ & $86.13 \pm 4.40$ \\
\hline $\mathrm{I} / \mathrm{R}$ & $45.75 \pm 3.03^{* *}$ & $42.38 \pm 2.50^{* *}$ & $37.38 \pm 3.12^{* *}$ \\
\hline LFAE & $64.63 \pm 3.29^{\# \#}$ & $61.88 \pm 3.27^{\# \#}$ & $58.75 \pm 2.66^{\# \#}$ \\
\hline \multicolumn{4}{|l|}{$\mathrm{CF}$} \\
\hline Control & $85.75 \pm 3.83$ & $83.13 \pm 3.87$ & $76.50 \pm 2.78$ \\
\hline $\mathrm{I} / \mathrm{R}$ & $58.88 \pm 3.56^{* *}$ & $52.50 \pm 2.45^{* *}$ & $51.63 \pm 3.66^{* *}$ \\
\hline LFAE & $73.75 \pm 3.80^{\# \#}$ & $68.38 \pm 4.15^{\# \#}$ & $64.63 \pm 3.28^{\# \#}$ \\
\hline \multicolumn{4}{|l|}{ HR } \\
\hline Control & $97.75 \pm 4.06$ & $92.63 \pm 4.69$ & $90.13 \pm 4.64$ \\
\hline $\mathrm{I} / \mathrm{R}$ & $81.75 \pm 3.37^{* *}$ & $74.75 \pm 4.71^{* *}$ & $73.50 \pm 3.25^{* *}$ \\
\hline LFAE & $88.38 \pm 4.44^{\#}$ & $84.88 \pm 4.67^{\#}$ & $80.88 \pm 5.00^{\#}$ \\
\hline
\end{tabular}

slices were immersed in phosphate buffer at $4^{\circ} \mathrm{C}(\mathrm{pH} 7.4)$ [16]. Heart slices were digitally imaged using a Canon camera. The area of infarcted part (pale) and viable part (red) was measured digitally using Image Pro Plus software. Infarct size was represented as percentage of the area of ischemia [17].

2.8. Assay of Oxidative Stress. When the perfusions finished, we froze the hearts under the condition of $-70^{\circ} \mathrm{C}$ to prepare for further testing. The frozen ventricles were crushed to powder by liquid nitrogen-chilled tissue pulverizer. For tissue analyses, weighed amounts of the frozen tissues were homogenized in appropriate buffer using microcentrifuge tube homogenizer. Then the SOD and malondialdehyde (MDA) were analyzed spectrophotometrically according to the instruction of the assay kits (Nanjing Jiancheng Bioengineering Institute, Nanjing, China).

2.9. Statistical Analysis. The results were expressed as mean \pm S.D. and analyzed by one-way analysis of variance (ANOVA). The values with $P<0.05$ were considered statistically significant. $P<0.01$ was considered very statistically significant. The analyses were carried out using the Origin 8.0 software (Origin Lab Corporation, Northampton, MA, USA).

\section{Result and Discussion}

3.1. The Aqueous Extract of Lavender Flower Improves Resumer of I/R-Induced Cardiac Function. The effects of treatment on LVDP, $\pm d p / d t_{\max }, \mathrm{CF}$, and HR during reperfusion in control group, I/R group, and treated hearts were shown in
Figure 1. The datum was recovery ratio between the value after 15, 30, and $45 \mathrm{~min}$ of reperfusion and one minute before stopping irrigation in Table 3 . When compared with the unprotected I/R hearts, exposure of $1 \mathrm{mg} / \mathrm{mL}$ extract during early reperfusion significantly improved functional recovery. The hearts underwent 20 minutes of ischemia time followed by $45 \mathrm{~min}$ of reperfusion and showed a remarkable reduction in the resumer of LVDP, $+d p / d t_{\max },-d p / d t_{\max }, \mathrm{CF}$, and $\mathrm{HR}$. The resumer of LVDP, $\pm d p / d t_{\max }, \mathrm{CF}$, and HR after $45 \mathrm{~min}$ of reperfusion was higher $\left({ }^{*} P<0.05\right)$ in hearts perfused with aqueous extract of lavender flower 10 minutes before ischemia.

3.2. The Aqueous Extract of Lavender Flower (LFAE) Attenuates I/R-Induced Enzyme Release in Rat Heart. Before ischemia, CK and LDH levels in the effluent from control group, I/R group, and LFAE $(1 \mathrm{mg} / \mathrm{mL})$ group are fundamentally the same. As shown in Table 1, after $20 \mathrm{~min}$ of ischemia followed by $20 \mathrm{~min}$ and $45 \mathrm{~min}$ of reperfusion, the leakage of $\mathrm{CK}$ and LDH markedly increased compared to that of control. The LFAE pretreatment significantly reduced the I/R-induced increase in $\mathrm{LDH}$ and $\mathrm{CK}$ release in rat heart.

3.3. The Aqueous Extract of Lavender Flower Reduced Myocardial Infarct Size following I/R Injure. At the end of reperfusion,myocardial infarct size was assessed using the TTC staining method. As illustrated in Figure 2(a), there was only a small piece of infarction in control group (Sham) and ischemia for $20 \mathrm{~min}$ followed by $45 \mathrm{~min}$ of reperfusion resulted in development of substantial myocardial infarcts, 


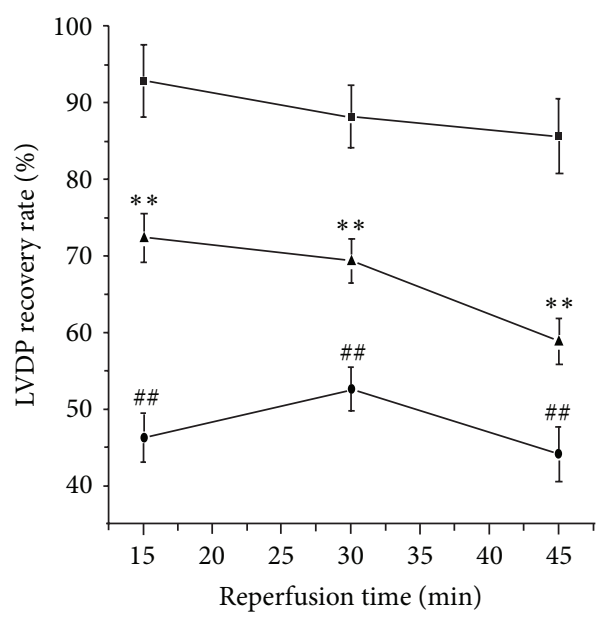

(a)

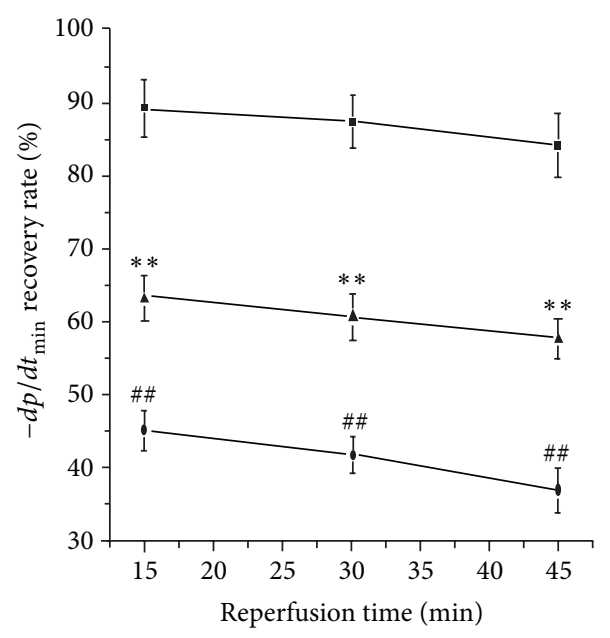

(c)

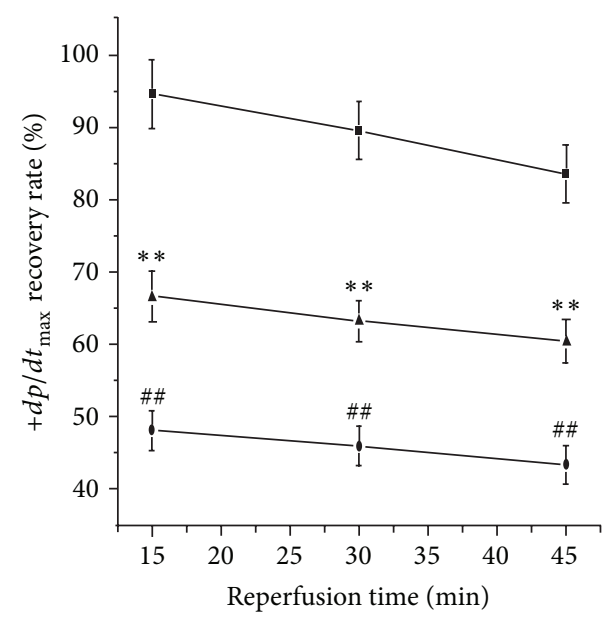

(b)

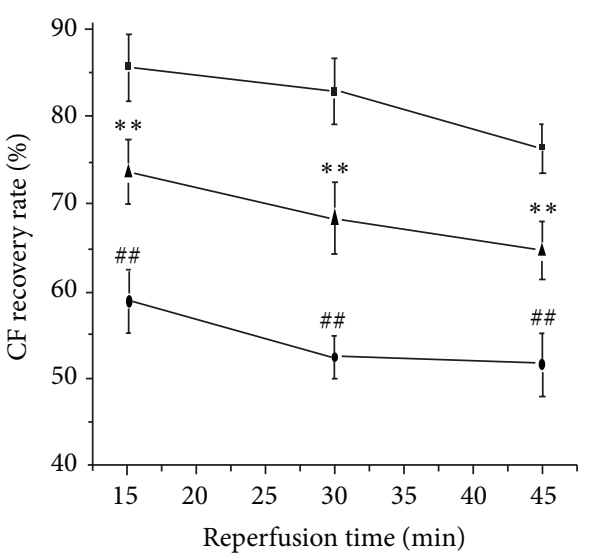

(d)

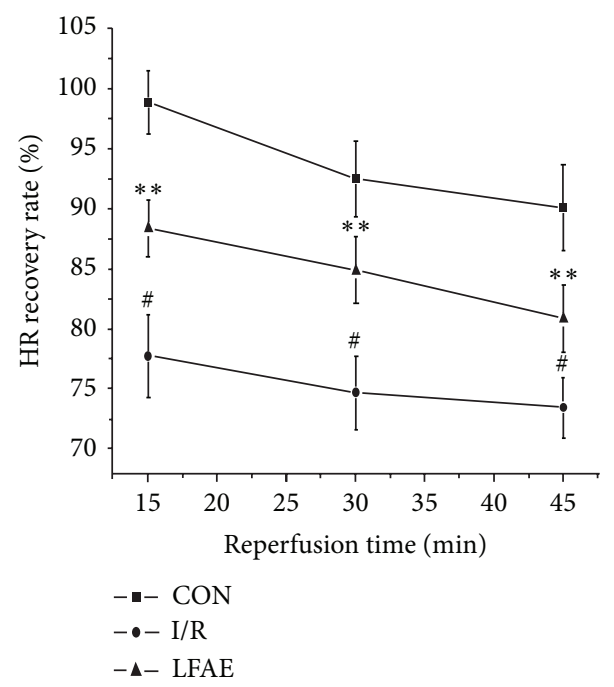

(e)

FIGURE 1: Effect of LFAE on cardiac function (LVDP, $+d p / d t_{\max },-d p / d t_{\min }$, CF, HR) in rats subjected to I/R $(\bar{x} \pm s, \%, n=8) .{ }^{* *} P<0.01$, compared with control group; ${ }^{\# \#} P<0.01$, compared with I/R group. CON: control group (Sham), I/R: I/R group, and LFAE: aqueous extract of lavender flower treatment group. 


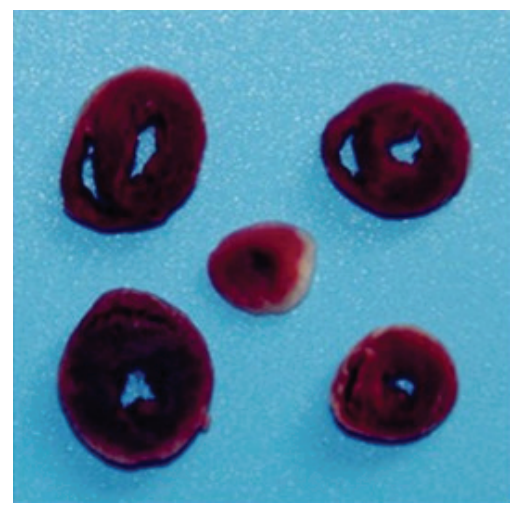

Control

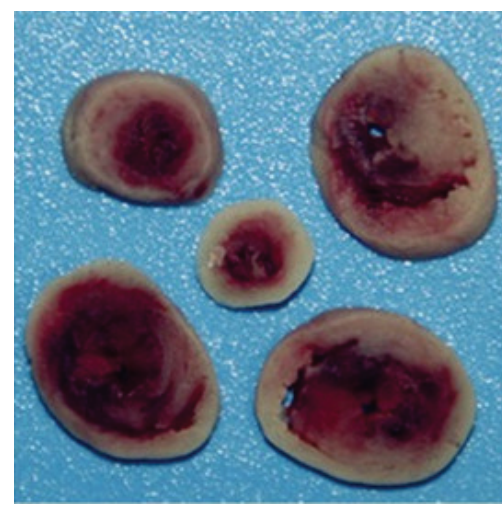

$\mathrm{I} / \mathrm{R}$

(a)

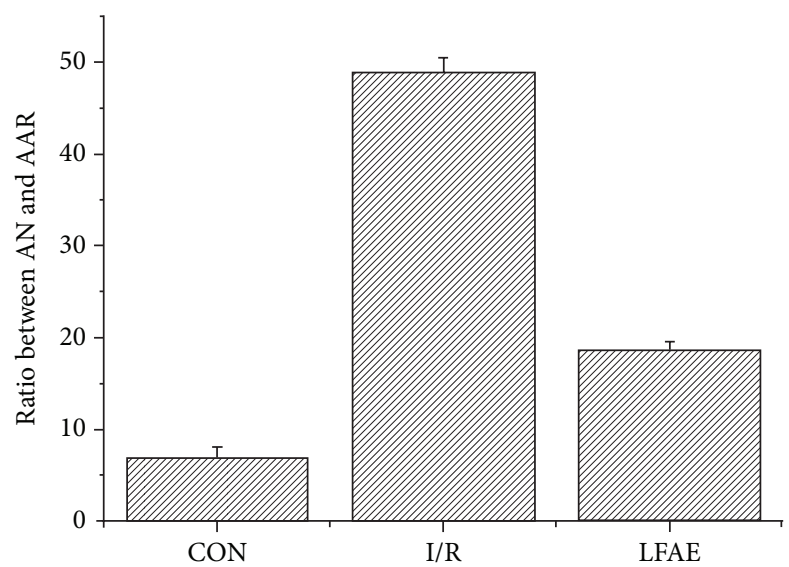

(b)

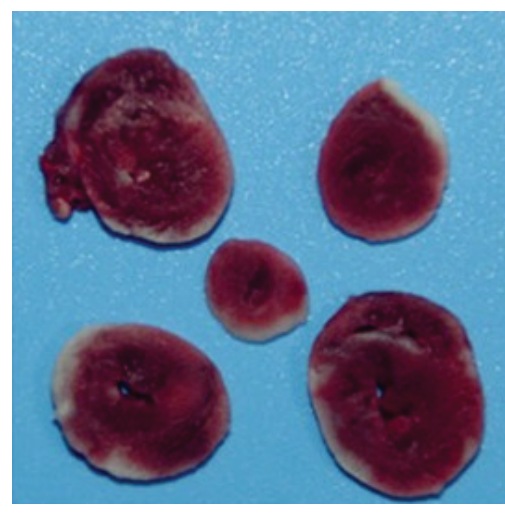

LFAE 
performed to examine whether LFAE affected the changes in MDA level and SOD activity induced by I/R. The present results illuminated that LFAE protected against myocardial I/R-induced injury, accompanied by the attenuation of MDA production and enhancement of SOD activity indicating that one of the mechanisms of the cardioprotection of LFAE was associated with its antioxidant effects.

\section{Conclusions}

In the present investigation, administration of LFAE significantly enhanced the resumer of I/R-altered cardiac function by blunting the reduction of left ventricular developed pressure (LVDP), maximum up/down rate of left ventricular pressure $\left( \pm d p / d t_{\max }\right)$, and coronary flow (CF) decreased by I/R injury. Also, LFAE treatment resulted in significant modulation of cardioprotection content, the SOD activity and MDA level. Therefore, it can be concluded that the aqueous extract of lavender flower possesses obvious protective effects on myocardial I/R injury, which may be concerned with the improvement of myocardial oxidative stress states.

\section{Conflict of Interests}

No conflicts of interests are declared by the authors.

\section{Acknowledgments}

This study was supported by the Natural Science Foundation of Shandong Province (no. ZR2011HL013) to Dong Wang and the Xinjiang Production and Construction Corps Fund for Distinguished Young Scientists (2011CD006).

\section{References}

[1] P. A. Grace, "Ischaemia-reperfusion injury," British Journal of Surgery, vol. 81, no. 5, pp. 637-647, 1994.

[2] H. Inafuku, Y. Kuniyoshi, S. Yamashiro et al., "Determination of oxidative stress and cardiac dysfunction after ischemia/ reperfusion injury in isolated rat hearts," Annals of Thoracic and Cardiovascular Surgery, vol. 19, no. 3, pp. 186-194, 2013.

[3] J. J. Ley, R. Prado, J. Q. Wei, N. H. Bishopric, D. A. Becker, and M. D. Ginsberg, "Neuroprotective antioxidant STAZN protects against myocardial ischemia/reperfusion injury," Biochemical Pharmacology, vol. 75, no. 2, pp. 448-456, 2008.

[4] Q. Yang, K. Yang, and A. Li, "microRNA-21 protects against ischemia-reperfusion and hypoxia-reperfusion-induced cardiocyte apoptosis via the phosphatase and tensin homolog/Aktdependent mechanism," Molecular Medicine Reports, vol. 9, no. 6, pp. 2213-2220, 2014.

[5] M. Khan, S. Varadharaj, L. P. Ganesan et al., "C-phycocyanin protects against ischemia-reperfusion injury of heart through involvement of p38 MAPK and ERK signaling," The American Journal of Physiology-Heart and Circulatory Physiology, vol. 290, no. 5, pp. H2136-H2145, 2006.

[6] J. J. Martindale and J. M. Metzger, "Uncoupling of increased cellular oxidative stress and myocardial ischemia reperfusion injury by directed sarcolemma stabilization," Journal of Molecular and Cellular Cardiology, vol. 67, pp. 26-37, 2014.
[7] D. K. Das and N. Maulik, "Antioxidant effectiveness in ischemia-reperfusion tissue injury," Methods in Enzymology, vol. 233, pp. 601-610, 1994.

[8] G. Chang, P. Zhang, L. Ye et al., "Protective effects of sitagliptin on myocardial injury and cardiac function in an ischemia/reperfusion rat model," European Journal of Pharmacology, vol. 718, no. 1-3, pp. 105-113, 2013.

[9] G. Woronuk, Z. Demissie, M. Rheault, and S. Mahmoud, "Biosynthesis and therapeutic properties of oil constituents," Planta Medica, vol. 77, no. 1, pp. 7-15, 2011.

[10] S. Sosa, G. Altinier, M. Politi, A. Braca, I. Morelli, and R. Della Loggia, "Extracts and constituents of Lavandulamultifida with topical anti-inflammatory activity," Phytomedicine, vol. 12, no. 4, pp. 271-277, 2005.

[11] B. Blažeković, S. Vladimir-Knežević, A. Brantner, and M. B. Štefan, "Evaluation of antioxidant potential of Lavandula $\mathrm{x}$ intermedia Emeric ex Loisel. "Budrovka": a comparative study with L. angustifolia Mill," Molecules, vol. 15, no. 9, pp. 5971-5987, 2010.

[12] M. Adaszyńska, M. Swarcewicz, M. Dzięcioł, and A. Dobrowolska, "Comparison of chemical composition and antibacterial activity of lavender varieties from Poland," Natural Product Research: Formerly Natural Product Letters, vol. 27, no. 16, pp. 1497-1501, 2013.

[13] M. Hancianu, O. Cioanca, M. Mihasan, and L. Hritcu, "Neuroprotective effects of inhaled lavender oil on scopolamineinduced dementia via anti-oxidative activities in rats," Phytomedicine, vol. 20, no. 5, pp. 446-452, 2013.

[14] L. R. Chioca, M. M. Ferro, I. P. Baretta et al., "Anxiolytic-like effect of lavender essential oil inhalation in mice: participation of serotonergic but not GABAA/benzodiazepine neurotransmission," Journal of Ethnopharmacology, vol. 147, no. 2, pp. 412418, 2013.

[15] J. L. Zweier, J. Fertmann, and G. Wei, "Nitric oxide and peroxynitrite in postischemic myocardium," Antioxidants \& Redox Signaling, vol. 3, no. 1, pp. 11-22, 2001.

[16] D. J. Bester, K. Kupai, T. Csont et al., "Dietary red palm oil supplementation reduces myocardial infarct size in an isolated perfused rat heart model," Lipids in Health and Disease, vol. 9, article 64, 2010.

[17] R. Ferrera, S. Benhabbouche, J. C. Bopassa, B. Li, and M. Ovize, "One hour reperfusion is enough to assess function and infarct size with ttc staining in langendorff rat model," Cardiovascular Drugs and Therapy, vol. 23, no. 4, pp. 327-331, 2009.

[18] A. Z. Xia, Z. Xue, W. Wang et al., "Naloxone postconditioning alleviates rat myocardial ischemia-reperfusion injury by inhibiting JNK activity," The Korean Journal of Physiology and Pharmacology, vol. 18, pp. 67-72, 2014.

[19] H. Lee, E. H. Ko, M. Lai et al., "Delineating the relationships among the formation of oxygen species, cell membrane instability and innate autoimmunity in intestinal reperfusion," Molecular Immunology, vol. 58, no. 2, pp. 151-159, 2014.

[20] S. Ma, Z. Zhang, F. Yi et al., "Protective effects of low-frequency magnetic fields on cardiomyocytesfrom ischemia reperfusion injury via ROS and $\mathrm{NO} / \mathrm{ONOO}^{-}$, , Oxidative Medicine and Cellular Longevity, vol. 2013, Article ID 529173, 9 pages, 2013.

[21] J. M. McCord, "Oxygen-derived free radicals in postischemic tissue injury," The New England Journal of Medicine, vol. 312, no. 3, pp. 159-163, 1985. 

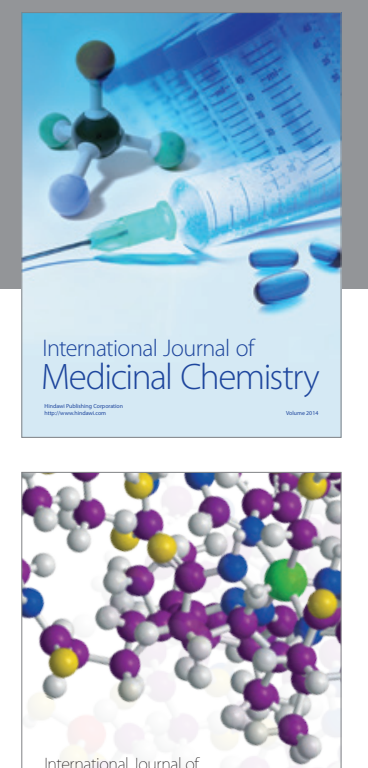

\section{Carbohydrate} Chemistry

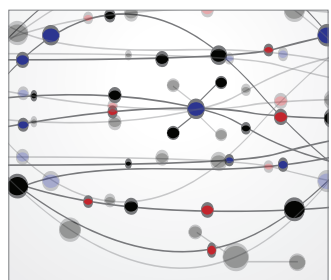

The Scientific World Journal
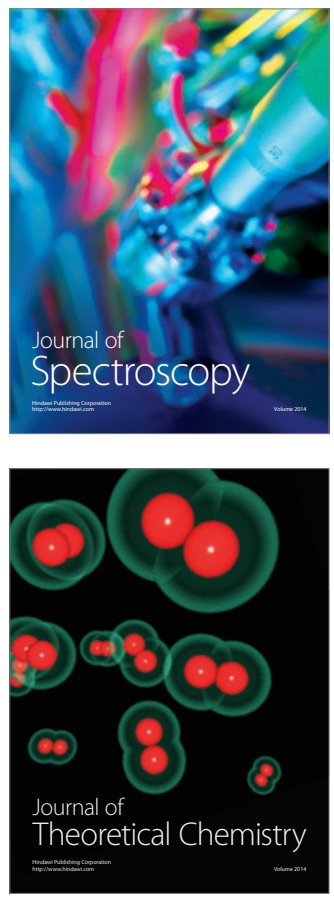
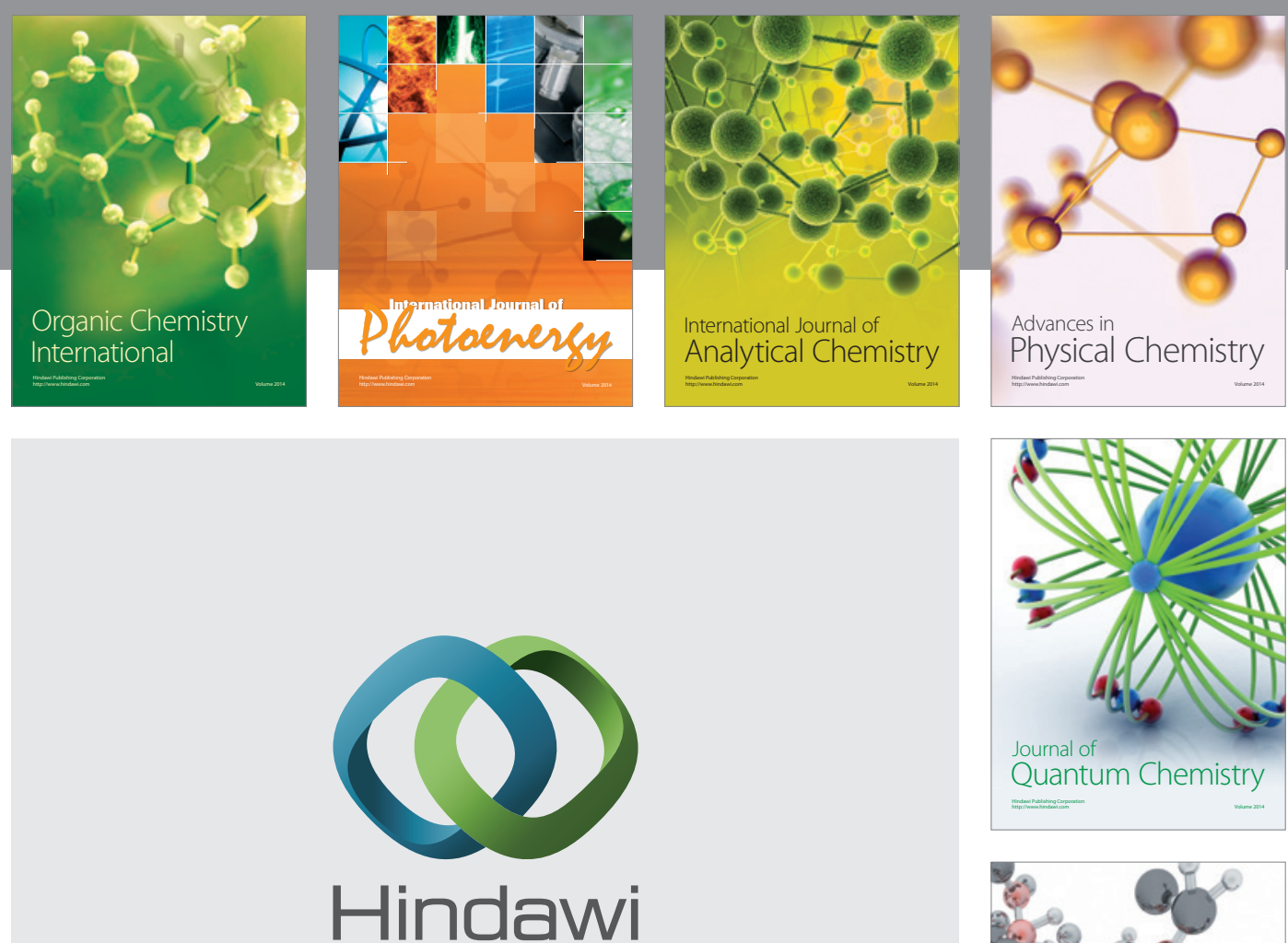

Submit your manuscripts at

http://www.hindawi.com

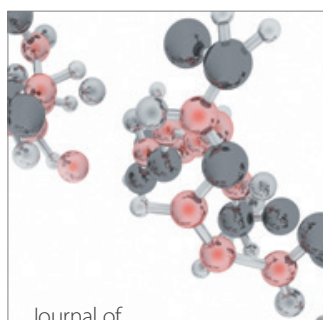

Analytical Methods

in Chemistry

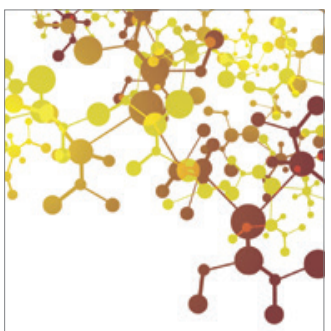

Journal of

Applied Chemistry

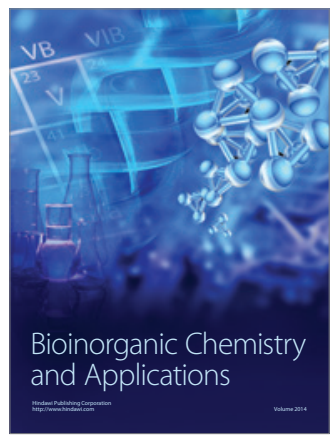

Inorganic Chemistry
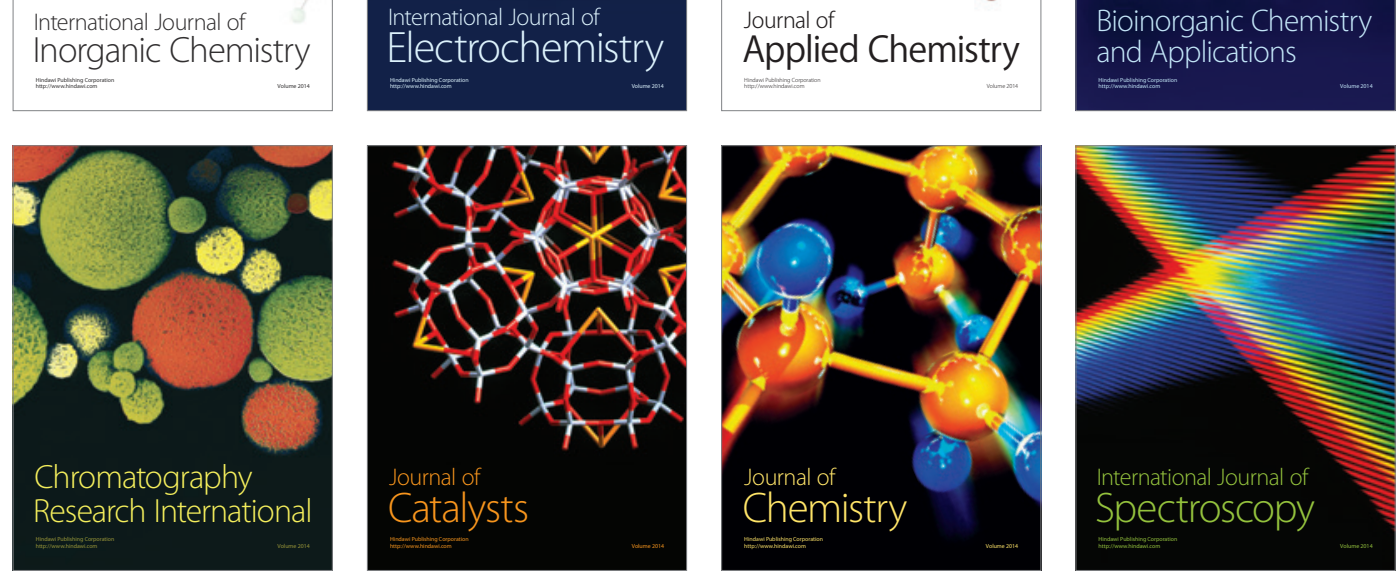